DOI: 10.12731/2227-930X-2016-4-56-62

\title{
A MODIFICATION OF THE METHOD CALLED "SUM" WITH THE TIME CONSTRAINTS OF DELIVERY OF GOODS
}

\author{
Prosov S.N., Gayazova Z.M.
}

The heuristic procedure considered the shift-daily planning of delivery routes method "amounts". We present the solution of the transportation problem or the routing problem in efficiency optimization of transportation.

Keywords: optimization; modification of the method called "sum"; efficiency; small-lot cargo delivery; shift-daily planning; transport problem; routing problem.

\section{Introduction}

The stage of development of the transport industry of considerable importance is the problem of increasing the efficiency of traffic optimization. The urgency of this problem is caused by the transporting cost of any product that is ultimately reflected in the price of goods.

To resolve this problem, you must properly and accurately organize transportation planning. Planning the transport of goods between supplier (GOP) and customer (GLP) location is generated in the process of solving transportation problems or routing problems.

Transportation problems, attempting to solve the problem of a large amounts, are of great interest to large firms. Making the right decisions reduces transportation costs by $10-15 \%$ [8], as well as more precisely drawn transportation schedules and routes of deliveries of goods.

One of these transportation problems is the problem of limited-time delivery of goods "just in time". Demand tasks are relevant 
for intra-bulk consignments of goods, since the delivery of goods or passengers is an important indicator in "megacities".

Formulation of the problem in this project is more complicated, but at the same time reflects the real process. The aim of the proposed variant solutions of the transportation problem is the drafting of the goods delivery route, striving for the minimum distance, as well as for accurate customer service at predetermined intervals of delivery.

\section{The general formulation of the transportation problem,} taking into account the limitations of time of delivery

The solution of problems related to the limited time of delivery of goods from the supplier to the consumer relates to vehicle routing problems. LED, for example, the transport problem can be described by the following situation. Required to organize transportation, which is carried out on the basis of having a single vendor, homogeneous products and a variety of consumer items of similar types of cargo. The car park is leased from the motor company, which provides the necessary for the implementation of the transport rolling stock. Under each car is determined daily route of cargo delivery to the customer with the exact location of the client, with full information on the volume of cargo transported and the nomenclature of products. On each route, there are imposed restrictions that must be followed. The volume of cargo must not exceed the load capacity of the car. The client must be serviced in exactly the specified time interval. Under a specified period of time means the vehicle arrival time to the client, the unloading of cargo and the departure time from the client. In addition, each client is served by a motor vehicle once.

\section{Objectives and methods}

\section{of transport planning small-lot cargo}

The main tasks of the distribution depending on the number of suppliers and customers, freight traffic, trucks and cargo vehicles, used 
supply chain and transport services to limitations on the time of delivery are as follows:

- Task "traveling salesman", time limits are not set, the number of suppliers of $\mathrm{m}=1$, the total volume of consumption of the goods in terms of ( $\Sigma$ Qi) is less than or equal to the vehicle load capacity (qk) $\Sigma$ Qi $\leq$ qk;

- Decomposition + method "amounts of" time limit is specified, the number of suppliers of $m=1$, the total volume of consumption of the goods in terms of ( $\Sigma$ Qi) greater vehicle capacity (qk); $\Sigma \mathrm{Qi}>\mathrm{qk}$;

- Method "functions benefit", specified time limit, the number of suppliers of $\mathrm{m}=1$, the total volume of consumption of the goods in terms of ( $\Sigma$ Qi) greater vehicle capacity (qk); $\Sigma \mathrm{Qi}>\mathrm{qk}$, or the total volume of consumption of the goods in terms of ( $\Sigma$ Qi) is less than or equal to the vehicle load capacity (qk) $\Sigma$ Qi<qkFigure 3.1. The interface of the electronic Atlas "INGIT";

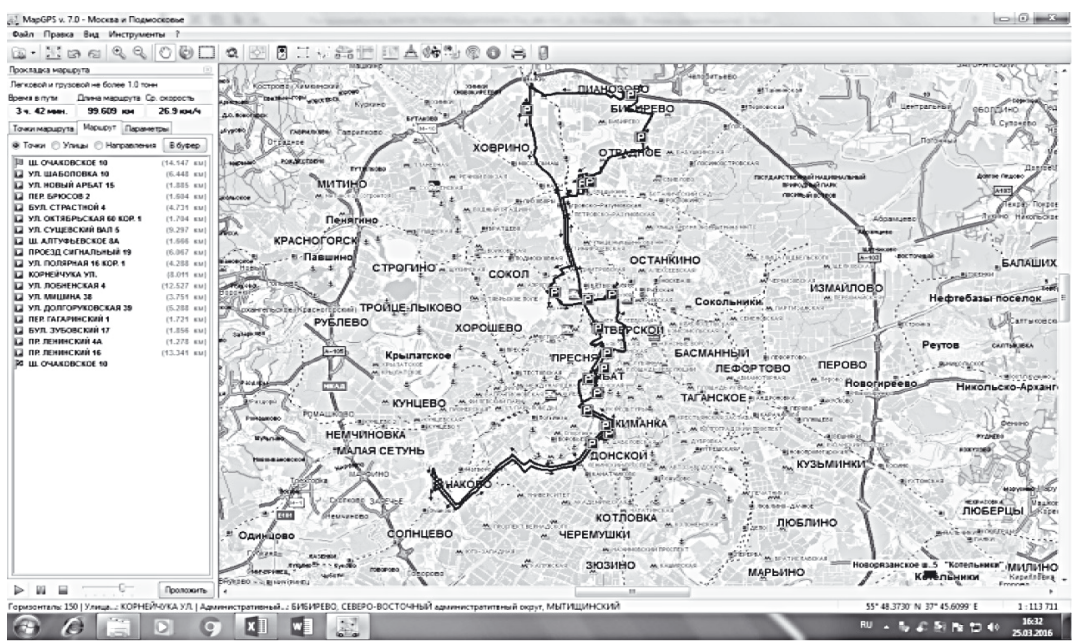

Fig. 3.1. The interface of the electronic Atlas "INGIT"

All the above objectives and methods of planning small-lot deliveries of cargo generated by an electronic atlas of highways "Streets of Moscow" INGIT (Figure 3.1) [6]. 


\section{The algorithm of heuristic procedures for shift-day planning of routes}

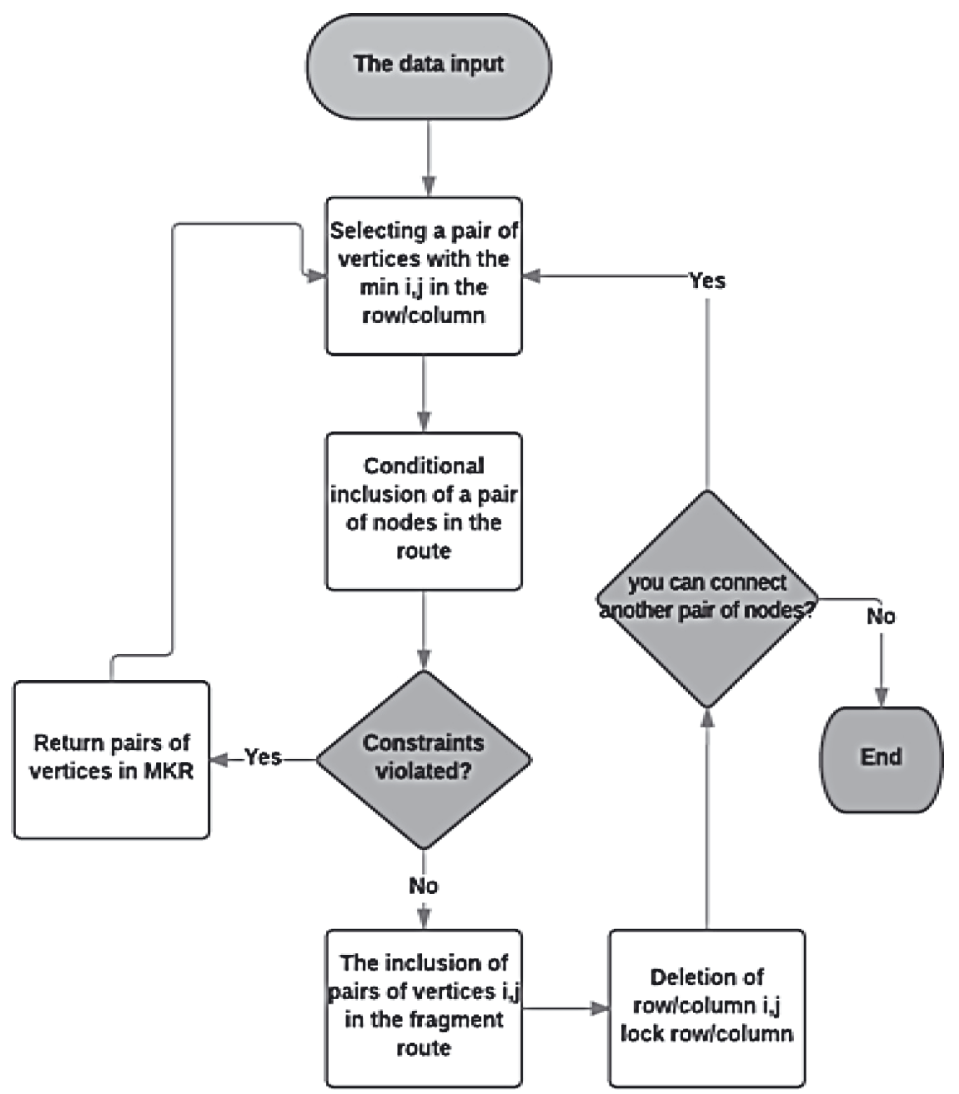

Fig. 4.1. Enlarged Block diagram

Consider the stages heuristic procedure of shift-day planning routes - the method of "sums" with regard to the delivery time slots as an example of distribution of goods from one warehouse to the set of consumers in a big city.

For clarity, planning routes presented enlarged block diagram (Figure 4.1). 
The first phase addresses the warehouse and clients coded in the top of the transport network model (MTS) (Figure 4.2).

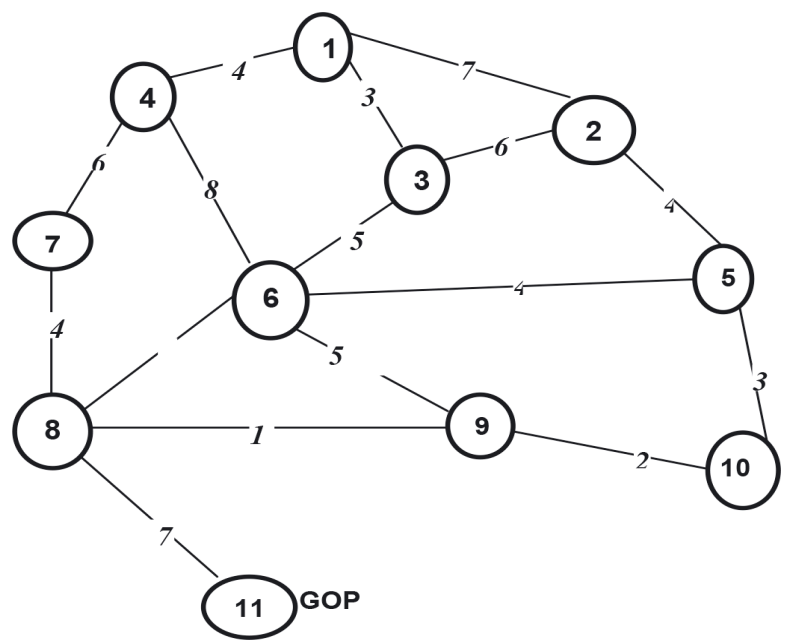

Fig. 4.2. The model of the transport network (MTS)

At the second stage construction of the routes "sums", followed by a breakdown of the general problem into several smaller tasks size. The breakdown is carried out in the following way:

1) the matrix of shortest distances (MKR) is most distant from the top of the warehouse.

2) on top of MKR determined minimum distance value in row distances from the warehouse to the consumer, or in a row / column most distant peaks, according to claim 1, if there are two nodes with the same minimum distance value, select any of them.

3) The third step is calculated evaluation $\Delta$ lij, covers all links to which can be connected to the top. calculated according to the formula $\Delta$ lij assessment to determine the sequence of vertices of a detour:

$$
\Delta^{\circ} \mathrm{ij}=1 \mathrm{i}^{\mathrm{o}},+\mathrm{l}^{\mathrm{o}} \text {, }
$$

$\mathrm{j}-\mathrm{li}, \mathrm{j}$ where li, about - the shortest distance from the point $\mathrm{i}$ to the GOP; 
$1^{o}, \mathrm{j}$ - shortest distance from the GOP to the point $\mathrm{j}$;

li, $\mathrm{j}$ - the shortest distance between points $\mathrm{i}$ and $\mathrm{j}$.

Calculate $i, j$ to evaluate the feasibility of replacing the pendulum routes with points $\mathrm{i}, \mathrm{j}$ one circular route that includes these items.

4) potential peak is included in the unit, where the assessment value

$\Delta^{\circ} \mathrm{ij}$ minimally subject to restrictions:. Cargo auto-mobile, the time spent on duty, the timing of delivery of cargo, etc. If at least one of the conditions is not satisfied, the top can not be included in the link. Consider other units or determine the next top with a minimum distance. With each subsequent step $\Delta^{\circ}$ ij will increase.

Formation of the route ends at the exhaustion of the list of vertices or no connectivity next item without violating the limits. In the latter case the begin to build the next route. The procedure is repeated to include all items in the routes.

\section{Conclusion}

At the current stage of economic development to build new approaches to transport planning is a thematic issue, so to improve the efficiency of traffic optimization in this article is offered to consider a modification of the method of "sums" in view of the limitations of time of delivery of goods from supplier to consumers.

As a result of the modifications made, the method of "sums" transportation problem or a routing problem has been solved, which ensure maximum efficiency to optimize traffic by reducing the total mileage of road transport, reduction of transport costs. Thanks to the results of increased levels of customer service, which is an important factor in a market economy.

\section{References}

1. Kozhin A.P., Mathematical methods in the planning and management of road transport of goods. A.P. Kozhin, V.N. Mezentsev. M.: Transport, 1994, $304 \mathrm{p}$. 
2. Models and methods of logistics theory: proc. the allowance for high schools / Under the editorship of prof V.S. Lukinsky. SPb.: Peter, 2003. $176 \mathrm{p}$.

3. Prosov S.N. Decomposition model the routing of freight in small batches, taking account of the places of storage of rolling stock. Industry monthly magazine «Motor transport enterprise» / S.N. Prosov, D.G. Moroz. M.: NPP transnavigatsiya, the Ministry of transport, 2014. S. 47-50.

4. Prosov S.N. Lecture notes for the course «Modeling of systems»/ S.N. Prosov. M.: OOO Tekhpoligraftsentr, Part 1 and 2, 2002.

5. Prosov S.N. Laboratory workshop on the course "Modeling of systems", Part 1. / S.N. Prosov. M.: MADI, 2001.

6. Prosov S.N. Model roundabout routing of freight shipments pomeshenie. Laboratory workshop on the course "Modelling transport systems" / S.N. Prosov. M.: MADI, 2004.

7. Prosov S.N. Heuristic model the routing of freight shipments small lots of packages UNL. Laboratory workshop on the course "Modelling transport systems" / S.N. Prosov. M.: MADI, 2008.

8. Prosov S.N. The heuristic procedure of shift-daily planning of delivery routes. Modern control technology in vehicle systems / S.N. Prosov, A.V. Zhukov. M.: MADI, 2007, pp. 112-117.

9. Sergeev V.I. Management in business logistics. M.: Filin, 2008. $772 \mathrm{~s}$.

DATA ABOUT THE AUTHORS

Prosov Sergey Nikolayevich, Ph. D., Associate Professor, Department of «Road transport»

State Technical University - MADI

64, Leningradsky prospekt, Moscow, 125319, Russian Federation

Gayazova Zifa Maksutovna, Undergraduate Student, Department of «Road transport»

State Technical University - MADI

64, Leningradsky prospekt, Moscow, 125319, Russian Federation zifa.gayazova@yandex.ru 